\title{
Metal Detection, An Essential Remote Sensing Approach for Historical Archaeologists
}

\author{
Charles M. Haecker ${ }^{1}$, Douglas D. ScotT ${ }^{2}$, and Patrick Severts ${ }^{3}$ \\ ${ }^{1}$ National Park Service (Retired) \\ ${ }^{2}$ Colorado Mesa University \\ ${ }^{3}$ Independent Researcher
}

\begin{abstract}
Over the last thirty years, metal detection has become an essential tool in historical archaeology, yet the majority of archaeologists still know relatively little about metal detectors. In this review we trace the increasing use of metal detectors in archaeological survey and research following several notable successes in archaeological surveys that proved their worth. To understand the differences between the two basic types of metal detectors used by archaeologists we briefly explain how they function and what their relative strengths and weaknesses are for archaeological research. Metal detectors are most commonly used in archaeological survey and after offering examples of how they have proved useful in recent Colorado research we lay out a methodology for a successful metal detection survey. In many ways the survey techniques, sampling designs, and intensive data recovery principles for metal detection work are akin to those principles and techniques used in standard archaeological research. These principles simply have been adapted to take advantage of the capabilities offered by this remote sensing device for discovering unseen historic sites and for better understanding how the patterning in metal artifacts at battle sites, historic trails, and Indian encampments sometimes can offer a totally new view of history.
\end{abstract}

Keywords: metal detection; remote sensing; historic sites; survey techniques; research goals

Archaeological research conducted in recent decades has utilized various remote sensing geophysical devices that include ground penetrating radar (GPR), Lidar, magnetometer, electrical resistance meter, electromagnetic (EM) meter, and metal detector. Unlike the other listed remote sensing devices, the metal detector has an unsavory reputation for many archaeologists because it has been misused by relic hunters, resulting in the wholesale loss of data from historic sites. But damning the metal detector as an instrument intended solely for looting is unreasonable; it can be a very important complement to an archaeologist's toolkit in situations where metal artifacts are likely to be part of the site's assemblage. Just as surface surveys, shovel tests, and excavation units are used to delimit sites, metal detectors help to identify metal artifacts to add to our understanding of a historic site's content, depth, and boundaries. Archaeologists who utilize metal detectors appreciate their simple operation, efficiency in locating metal artifacts, and usefulness in determining areal extent and internal complexity of historic sites.

\section{Historical Background}

The concept of using metal detectors as an archaeological remote sensing device is not new. In 
1947, Edwin Luce, Superintendent of Little Bighorn Battlefield National Monument, experimented with a World War II-era mine detector in order to find battle-related artifacts within the park. Luce's experiment failed, probably because the complexity of tuning this early type of metal detector made it inadequate to find small items, such as cartridge cases and bullets. Beginning in 1956, National Park Service (NPS) historian Don G. Rickey, one of the leading experts on the Plains Indian wars, teamed up with archaeologist Jesse Vaughn to initiate a multi-year metal detection program at Little Bighorn Battlefield. Using a more technologically advanced metal detector than the one used in 1947, Rickey and Vaughn identified a pattern of cartridge cases deposited along the soldiers' perimeter line at the Reno-Benteen defensive position. During ensuing years, they identified eight concentrations of cartridge cases that reflected the positions held by Lakota and Sioux warriors engaged in the attack on the Reno-Benteen position (Greene 1986:32). This metal-detection survey project continued within the park until 1964 and resulted in a revised interpretation of battlefield events.

Based in part on the success of metal detection at Little Bighorn Battlefield National Monument, several other archaeologists began to incorporate this remote sensing method into their investigations of historic battlefields and military encampments. ExamplesincludetheRevolutionaryWarContinental Army campsite at Valley Forge (Parrington et al. 1984:130-131); the 1836 Texian Independence battlefield of San Jacinto, Texas (Cartier and Hole 1972); and the 1846 U.S.-Mexican War battlefield of Palo Alto, Texas (Baxter and Killen 1976; Haecker 1994). Metal detection technology also gradually improved in order to meet growing popular interest in prospecting for precious metals and relic hunting. Yet the archaeological community as a whole was still hesitant to consider metal detection as a viable remote-sensing approach. Perhaps this was due to the inability of metal detector models available at that time to accurately locate small metal objects, but certainly the profession's growing association of the metal detector with illicit relic collecting must also have been a factor.

Interestingly, in the 1980s a study of the Little Bighorn Battlefield once again opened archaeologists' eyes to the possibility of using metal detectors for survey and research. In 1983, Little Bighorn Battlefield was extensively burned by a grass wildfire; this offered the opportunity for NPS archaeologists to conduct a comprehensive survey of the battlefield in the hope of identifying surface artifacts that had been previously obscured by vegetation growth. Accordingly, in 1984 archaeologists Douglas Scott and Richard Fox initiated an inventory survey that employed conventional inspection of the surface. After surveying some 800 acres, Scott and Fox recovered ten battle-related artifacts. They then employed the assistance of avocational metal detectorists, who surveyed a series of sample transects over the same area. This survey method resulted in the recovery of over 5,000 artifacts.

According to Connor and Scott (1998), in order to cover the same area using a 10-meter shoveltesting interval, it would have required 45,500 shovel test units; a 5-meter interval would have necessitated 91,000 units. This hypothetical array of shovel tests was overlaid onto a map that illustrated the point-provenienced artifacts discovered as a result of metal detection. This map overlay indicated that less than one percent of the recovered metal artifacts would have been found using conventional shovel testing techniques. If systematic shovel testing was employed, the ten weeks of field work required for the metal detecting inventory would have been inadequate to complete the work, and by their estimates would have yielded less than 50 artifacts (Connor and Scott 1998:78).

Publications of their archaeological findings and the resulting new interpretations of the battle of Little Bighorn (Scott and Fox 1987; Scott et al. 1989) provided the conclusive evidence needed to demonstrate the efficacy of metal detection when used in a suitable sampling design. Since the 1990s, the use of metal detectors in archaeological survey projects in the United States and Europe has increased exponentially. The Little Bighorn Battlefield archaeology project also presented basic fieldwork sampling techniques designed for metaldetection surveys, with researchers able to modify these techniques in order to meet their own specific research requirements.

As a consequence, historic battlefields and military encampments that encompass hundreds and even thousands of acres can now be sample 
surveyed, yielding artifact data derived from metal detection with point-specific coordinates for each artifact. The resulting artifact patterning has permitted independent interpretations of a given historic battle without relying solely on official period documents and oral histories, as was typical prior to metal detection surveys of battlefields. In fact, the NPS American Battlefield Protection Program (ABPP), in its recent review of proposed surveys of historic battlefields, now expects to see research designs that utilize a suite of complementary remote sensing techniques such as metal detection (Balicki and Espenshade 2010:3; Kristen McMasters, personal communication 2012).

\section{Other Project Examples}

Of course, metal detection is not limited to conflict sites. For example, Hardesty (1997) combined conventional visual inventory and testing techniques with metal detector sweeps to find and study one of the Donner Party's 1846 winter camps. Metal detectors have also been used to identify sites even when no surface evidence exists. This was the case when a team of archaeologists verified the presence of several previously unknown Apache encampments by metal detecting ridge crests, a landform favored by Apache bands for defendable encampments (Haecker 2002). Metal detection is useful in extrapolating the actual areal extent of a historic site, rather than depending solely on the visual identification of a surface artifact scatter (Haecker and Wegman-French 2010). Researchers engaged in determining the true location of Traveler's Rest, the site of the 1805 Lewis and Clark Corps of Discovery encampment in Montana, employed several complementary remote-sensing techniques that included metal detection. Discovery of diagnostic metal artifacts via metal detection provided essential physical proof that supported other lines of remote sensing evidence to finally identify the site's location (National Park Service 2005).

Metal detection has been conducted in Colorado by archaeologists employed in the private sector, universities, and the federal government. Colorado archaeological surveys that have utilized metal detectors include, for example, the 1998 and 1999
NPS projects that located and recorded the 1864 Sand Creek Massacre site. This project, under the direction of archaeologist Douglas Scott and historian Jerome Greene, involved a multidisciplinary research team that included historians, ethnologists, property owners, Native American informants, and over 20 metal detectorists, the latter including both federal archaeologists and avocational volunteers. The sample survey recovered 401 artifacts associated with the site. Artifact distribution patterns clearly indicated the location of the Indian village that was attacked and destroyed by Colonel Chivington's Third Colorado Volunteers. This discovery eventually led to legislation in 2000 that established the Sand Creek Massacre National Historic Site (Greene and Scott 2004).

In 2014, NPS conducted a follow-up sample survey within Sand Creek Battlefield National Historic Site, in an attempt to find evidence of routes of escape taken by those who fled from the village. Metal detection sweeps identified where warriors took positions to check a cavalry attack, and where groups of Indians were presumably killed (Haecker 2015).

Alpine Archaeological Consultants, Inc., regularly utilizes metal detectors to identify metallic artifact concentrations associated with subsurface structural remains, thereby facilitating placement of test units (Horn et al. 2003). They also use metal detection as a means to define the areal extent and depth of metallic artifacts within historic sites in order to assess the research potential of archaeological deposits where surface artifacts are present but sparse (Millward et al. 2012).

Curtis Martin and Michael Brown of Dominguez Archaeological Research Group (DARG) have used metal detectors to identify Ute hunters' encampments on the Northern Colorado Plateau as part of the Colorado Wickiup Project. Metal detection is a major factor in determining the actual areal extent of wickiup sites and helps guide where test units should be placed in order to retrieve nonmetallic artifacts, such as seed beads and bone (Martin 2016: 88-98; Martin and Brown 2010; Martin et al. 2011).

RMC Consultants has also used metal detection in their Colorado research with Paleocultural Research Group (PCRG) on the Baca Mountain Tract "New Lands" landscape analysis in Saguache 
County. Based on its previous work at the Bunker Site (5SH614), RMC recognized the need to use metal detection to better define a segment of Old Spanish National Historic Trail that bisects the site. Systematic metal detection produced scores of metal artifacts that aided in reconfiguring the site boundary as well as enhancing our understanding of historic period trail use by Native Americans and Euro-Americans during the late eighteenth and early nineteenth centuries (Martorano et al. 2014).

In 2008, the BLM-Little Snake and White River Field Offices wanted to determine if there were archaeological sites, features, or objects on public land on and adjacent to Thornburgh Mountain in advance of oil and gas leasing in the area of potential effect. Another consideration for the inventory was to determine the potential effects of such development on the nearby 1879 Ute IndianU.S. military battle site of Milk Creek, Colorado. Archaeologist Douglas Scott conducted a metal detection survey of the 740 -acre project area, producing five isolated historic metallic artifacts; other recovered metal objects were less than 50 years old. This information, combined with a lack of prehistoric artifacts noted from visual inspection of the ground surface, provided information that supported a recommendation that there would be no effect to areas associated with the Milk Creek battle site (Scott 2008).

In 2013, the NPS-Heritage Partnerships Program conducted an assessment of the Trujillo Homestead National Historic Landmark (NHL) near Alamosa, Colorado, to determine if proposed stabilization of the homestead barn might adversely affect subsurface cultural remains. In addition to placing shovel tests and excavation units within the area of potential effect, metal detection sweeps clearly identified the actual areal extent of the trash scatter associated with the use of the barn, which was constructed sometime prior to 1885 . Together, these discovery phase investigations indicated that the stabilization efforts were unlikely to disturb any significant subsurface cultural remains (Haecker 2014).

\section{Geophysical Principles of a Metal Detector}

The following information regarding the geophysical principles of a metal detector is a summation of Connor and Scott's 1998 article in Historical Archaeology on the archaeological use of metal detectors. This article is highly recommended for those who desire a more in-depth primer on this subject. Although it is not essential to be steeped in metal detector operations minutiae, we believe that a general understanding as to how a metal detector operates is useful. Without proper guidance it is all too easy to make ill-advised decisions as to the type of metal detector needed for the project in mind. Metal detector makes and models differ in various ways and both time and money can be wasted if one does not comprehend a particular machine's capabilities and limitations.

All metal detectors work on the same general principles and have a basic configuration that includes a handle, coil, cable, and a metal box housing the battery and tuning apparatus (figure 1). The two basic metal detector types typically

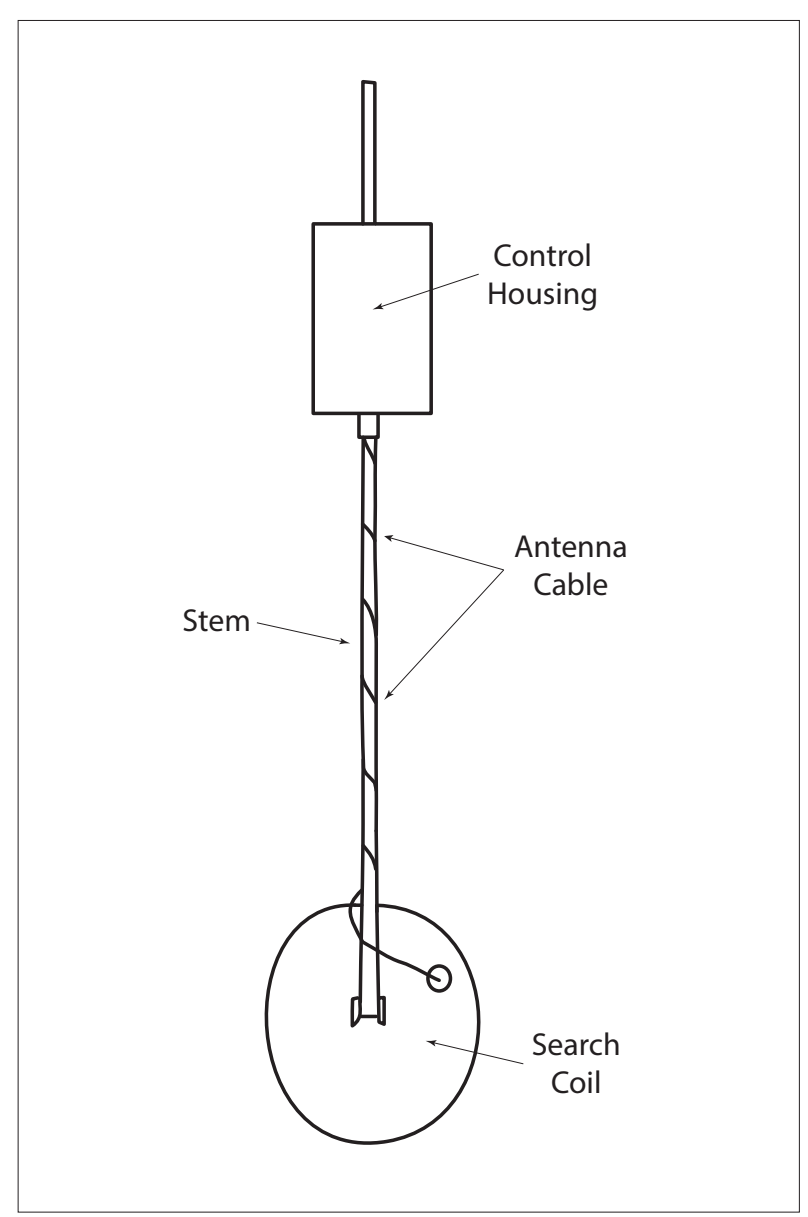

Figure 1. Schematic drawing of a metal detector with its principal elements identified. 
used in archaeological metal detecting are very low frequency (VLF) and pulse induction (PI) detectors.

A VLF detector sends a continuous electrical current into the ground to determine whether materials that are conductive or resistive to electrical current are present (figure 2). An object that conducts electricity easily (i.e., conductive) is slow to react to changes in the current. An object that does not conduct electricity easily (i.e., resistive) is quick to react to changes in the current. A VLF metal detector provides an audible tone or visual indicator to signal the presence of a metallic object and what the object is likely to be, within a range of certain metals. The nature and quality of the components in the control housing fundamentally differentiate the basic, less expensive machines from the more expensive models, which have more elaborate functions and displays, and exhibit a greater range of discrimination as well as sensitivity to certain types of metallic artifacts.

On most archaeological surveys, VLF detectors provide dependable survey data results. Situations do arise, however, when this detector type falls short of optimal performance. One drawback of a VLF detector is that it will occasionally generate false signals due to iron- or saline-rich soils, or highly mineralized rocks. The "noise" of these false signals, in turn, may mask or hide the signals that emanate from smaller metallic artifacts imbedded in such a soil matrix. Some VLF models offer features that will screen out false signals, but at the cost of lost information about the depth of the artifact. In addition, the capability of a VLF metal detector may be limited by conditions such as thick vegetation cover, waterlogged soils, and electro-magnetic fields generated by power lines and underground electrical cables.

Commonly available VLF metal detectors vary in their cost, sensitivity, and quality of construction. ${ }^{1} \mathrm{~A}$ VLF metal detector such as the Minelab CTX $3030^{\circ}$ often can detect a metallic object the size of a penny to a depth of $30-35 \mathrm{~cm}$ below surface, especially when used on optimal ground types such as quartz sands or limestone-derived soils. A less expensive model (such as the Tesoro Lobo SuperTraq ${ }^{\circledR}$ ), when used on the same above-described soil conditions, typically can detect a penny-sized object only to a depth of 15-20 cm below surface.

In contrast to a VLF detector, a pulse induction or PI detector sends powerful intermittent bursts (pulses) of current through a coil of wire. Each pulse generates a brief magnetic field. When the pulse ends, the magnetic field reverses polarity and collapses very suddenly, resulting in a sharp electrical spike. A PI-based metal detector can send electrical pulses into the ground at a rate ranging from several dozen pulses per second to over a thousand, depending on the model or brand. This type of metal detector is useful in situations where VLF metal detectors would have difficulty, such as

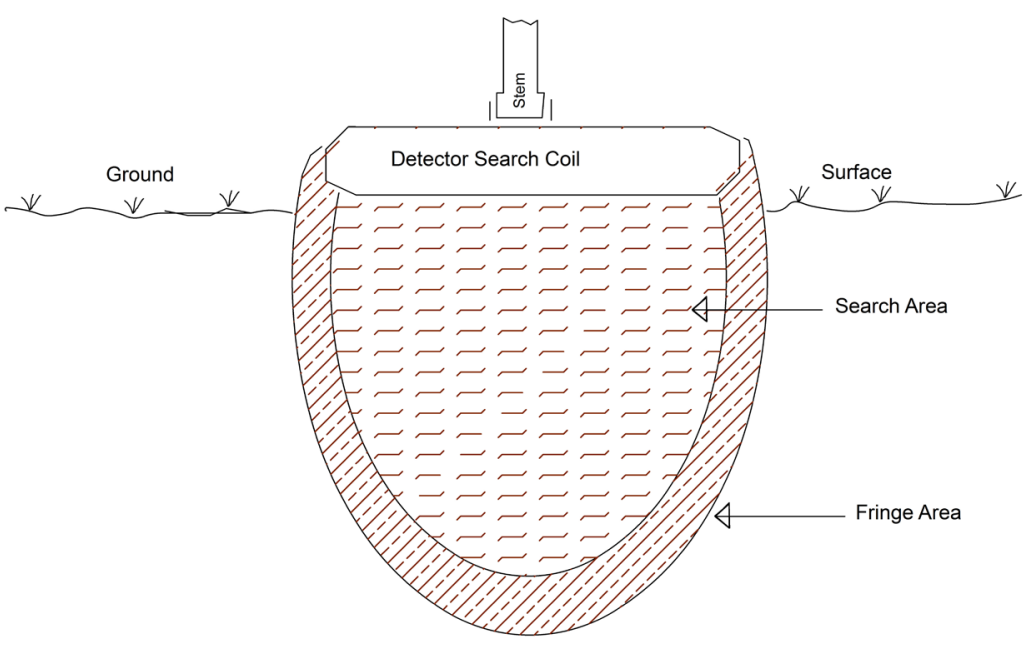

Figure 2. Electromagnetic fields generated by the concentric coil/antenna on a metal detector. 
in areas that have highly conductive material in the soil or general environment. A PI detector also can identify metallic objects at depths far greater than what can be reached by a VLF metal detector. For example, the Minelab GPX $5000^{\circ}$ can identify a metal object about the size of a match head down to a depth of over one meter. Yet PI metal detectors are poor at discriminating between various metals because the reflected pulse length of various metals cannot be easily separated.

Basic operation of most VLF metal detectors can be learned quickly. Exceptions are the VLF multifrequency machines and PI machines, which take many hours of hands-on experience in order to use effectively. As with any tool, the more experienced and skilled the operator, the more efficient the work and the better the results. Since the skill of the operator is one of the most important variables, many projects have relied on experienced volunteer detector operators.

There is a wide variety of metal detector makes and models from which to choose, with prices running as low as $\$ 100.00$ to as much as $\$ 10,000.00$. Although the cost of a metal detector is an important consideration when selecting a machine, one should keep in mind that a relatively inexpensive metal detector may not provide full value for what is desired; for example, an inexpensive machine may not identify metal targets at a depth greater than 10 $\mathrm{cm}$ below surface. There are a number of questions one should consider when selecting a particular detector make and model, especially if it will be the archaeologist's only machine:

- Is the machine rugged in its construction, simple to maintain, and ergonomically well-designed so that one could swing the detector for an hour or so and not experience arm fatigue?

- Is the control box water proof or at least water resistant?

- Does the model offer interchangeable types of coils so that it may be used in different types of soil and terrain?

- Can a novice to metal detection quickly master its operation?

- Is the detector accurate in pinpointing a targeted object?

For these and other reasons, an archaeologist who conducts metal detection should possess at least one VLF machine that will meet the challenges of a variety of terrains and soil types, while also obtaining a high standard of artifact recovery.

\section{Metal Detection Survey Techniques}

Metal detection surveys vary in their methodologies and goals, but they often share certain basic procedures. They typically begin by sweeping a series of contiguous transects across a defined area. Wooden- or nylon-stemmed pin flags are used to mark each target, or discovery, as metal pin flags will confound a metal detector. The target can either be investigated at the time of its discovery or after the completion of the survey of the study area. Each target should be assigned a provenience number and we recommend placing the number on a piece of masking tape, which can then be placed on the pin flag. Finally, a mapping instrument such as a GPS device with sub-meter accuracy or a total station can be used to determine UTM or local grid coordinates for each discovery.

If the artifacts are to be collected as part of the survey plan, the artifact collection bag should provide the provenience information on the bag exterior, as well as on a provenience card placed inside the bag. Small artifacts, such as a straight pin, should be placed in a bag or container appropriate to the artifact's size and then placed in the larger bag. In a non-collection survey, an analysis is conducted in the field and the artifact is reburied at the level of discovery. All pertinent data regarding each artifact, such as its provenience number, UTM coordinates, description, photo number, and so forth, should be listed on an artifact record sheet, or an in-field GIS or total station data collector.

Transect width should permit unhindered swinging of the detector, typically in an overlapping, figure-8 sweeping motion. Transects can be delineated first by laying a non-metallic tape measure along a base line to determine each transect placement and width, and thereafter marking the boundaries of each transect with string, pin flags, or wooden lathe placed along an axis perpendicular to the base line. This technique will ensure comprehensive coverage of the survey area. A cursory review of metal detection survey reports suggests that 1.0 and 1.5 meter-wide formal transects are favored (figure 3), but there is no rule as to how wide or how long each transect should be. 


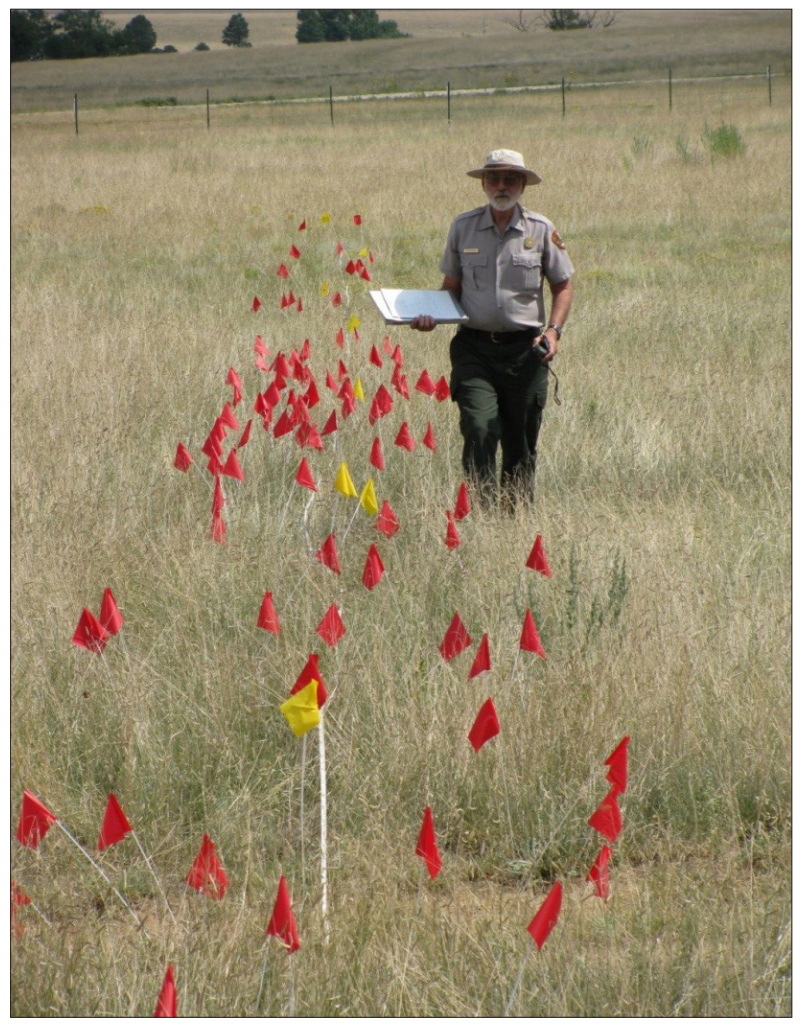

Figure 3. Metal detection of 1 meter-wide transects, to determine density of subsurface metallic artifacts within a 24 by 27-m trash dump, Second Fort, Fort Union National Monument. Each red pin flag denotes the location of a subsurface metal artifact; only 12 artifacts are visible on the surface. As a result of this sample survey, it is estimated that over 2,000 metal artifacts are within this feature (Haecker 2011).

Alternatively, transects can be traversed without placement of transect controls (figure 4). In this situation, the surveyor detects along a fixed bearing to complete each single transect and then begins the next transect by heading in the opposite direction approximately adjacent to, or overlapping, the previously surveyed transect. Since the metal detector operator is not constrained by formal transect boundaries, the length of the arm that is swinging the detector determines the lateral extent and width of the figure- 8 sweeping motion. If one is interested in quickly determining presence/absence of targets within and around a small-dimensioned feature such as a wickiup, then a more focused survey design rather than a transect design can be used.
Sample Survey Design

Archaeological metal-detection projects can have a sample universe comprised of hundreds of acres and may result in the recordation of thousands of targets. A project such as a historic battlefield survey may engage the services of 25 or more metal-detector operators, target excavators, and GPS data collectors. Such a large operation is likely to also require at least one in-field curator, a forms recorder/compiler, a photographer, and at least one in-field artifact analyst. The following paragraphs describe the operation of a typical large-scale survey.

First, a survey unit (for example, a block measuring $200 \times 200 \mathrm{~m}$ ) is demarcated using flagged wooden lathe placed every 5 or 10 meters to indicate transect spacing and termini. Then, metal-detector surveyors are aligned at one end of the survey unit, with each surveyor positioned at a transect lathe. All surveyors proceed aligned with one another toward their respective transect termini lathes located on the opposite side of the survey block (figure 5). The surveyors place non-metallic (nylon- or woodstemmed) pin flags at the locations of identified subsurface metallic readings, commonly termed targets, and then proceed onward.

Follow-up excavation teams, using metal detectors and hand-held metal detector pin pointers, subsequently expose the targets (figure 6). Sometimes the target may prove to be a highly magnetic rock, a false reading, or an elusive object that cannot be readily found. It is also possible for surveyors to excavate their own targets either at time of discovery or after completion of surveying their respective transects. The size of the project, the number of personnel, and their level of training often determine the best division of labor.

Having a GPS data collection team is an efficient way to determine each target's UTM coordinates and to assign a target number that can be taped or written onto the target's pin flag. An expert artifact analyst is also a tremendous aid in making basic artifact type determinations and deciding whether an item should be collected, if collection is called for in the survey design. If the object is to be collected, a curation expert can assess the artifact's condition, fill out the appropriate provenience data for bag or container labels, and ensure that the artifact is placed inside the correct bag. 


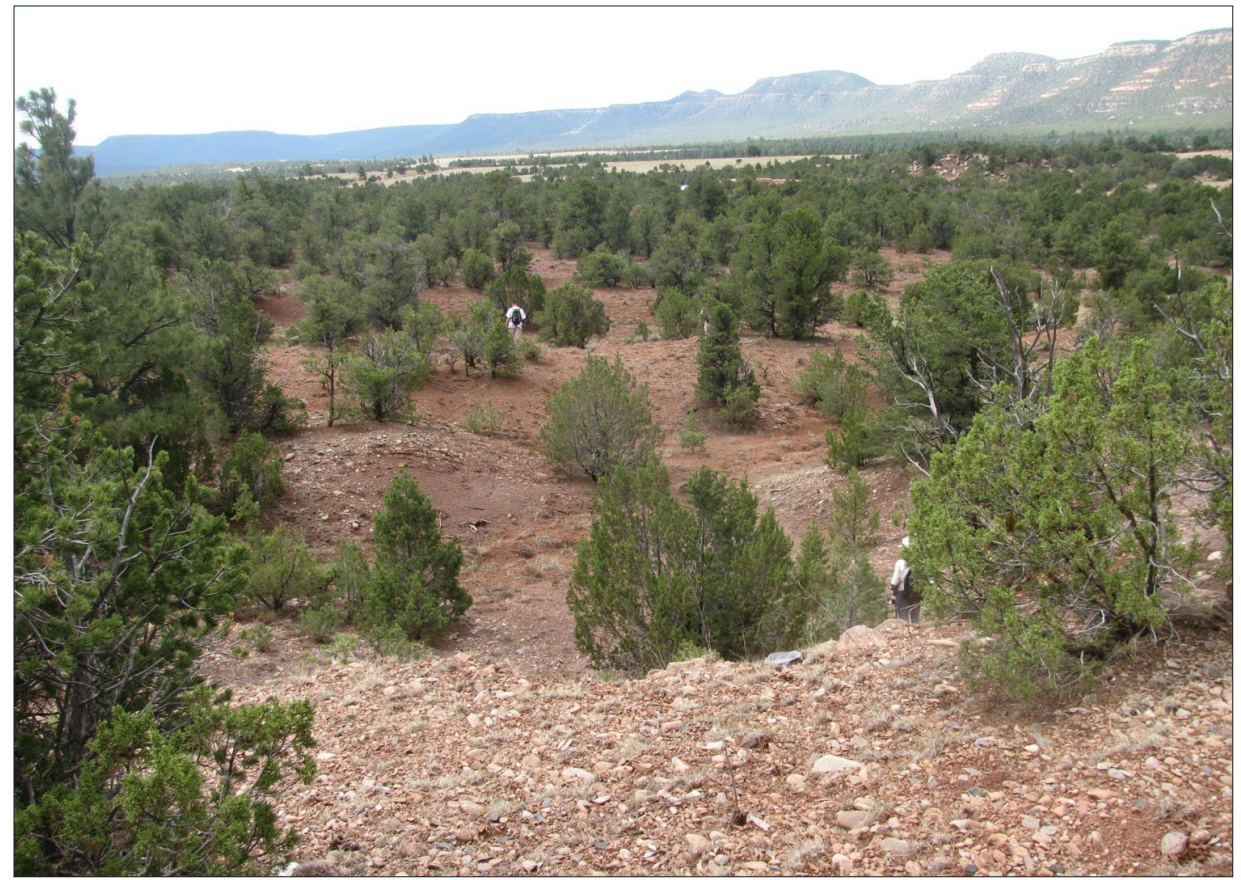

Figure 4. Metal detection

reconnaissance sample survey over broken, wooded terrain, Pecos Pueblo National Historical Park, New Mexico. The two detectorists in the photo are widely spaced, with each surveyor following a GPS-generated bearing (Haecker 2012).

Figure 5. Metal detectorists in line, spaced approximately 3 meters apart, Pecos Pueblo National Historical Park. Detectorists are surveying within a previously identified early Spanish Colonial Period encampment, and requiring greater recovery of diagnostic artifacts (Scott et al. 2014).

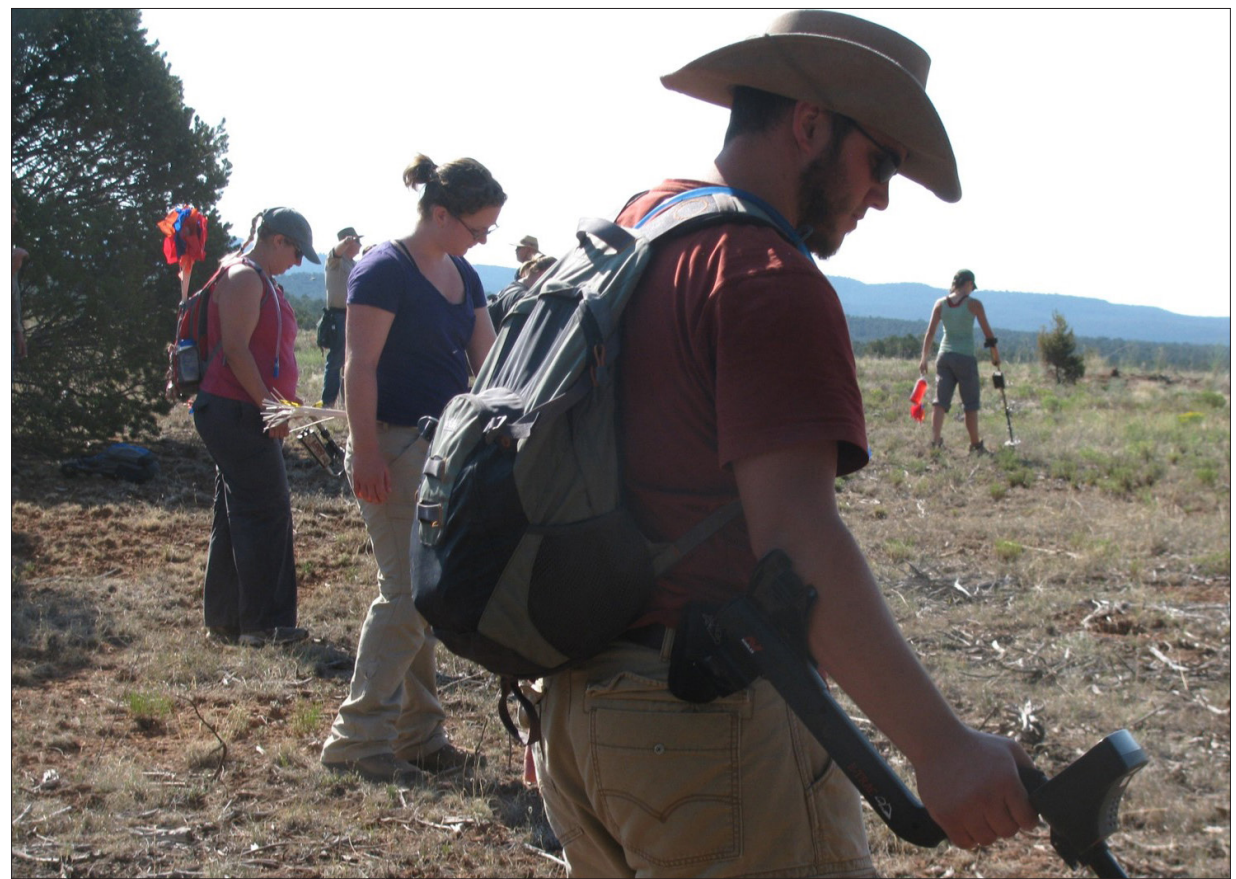

A forms compiler can speed completion of the forms, whether they be on paper or in an electronic data collection system (figure 7). They also typically collect the bagged artifact for final tallies. A field photographer can either photograph each collected artifact at its place of discovery or later in the day in a more controlled setting.
Artifacts, forms, and electronic data should be collected at the end of each day of survey. These data may be paper forms to be gathered into a binder or GPS data that is paired with artifact descriptive data to be downloaded onto a mapping software program. 


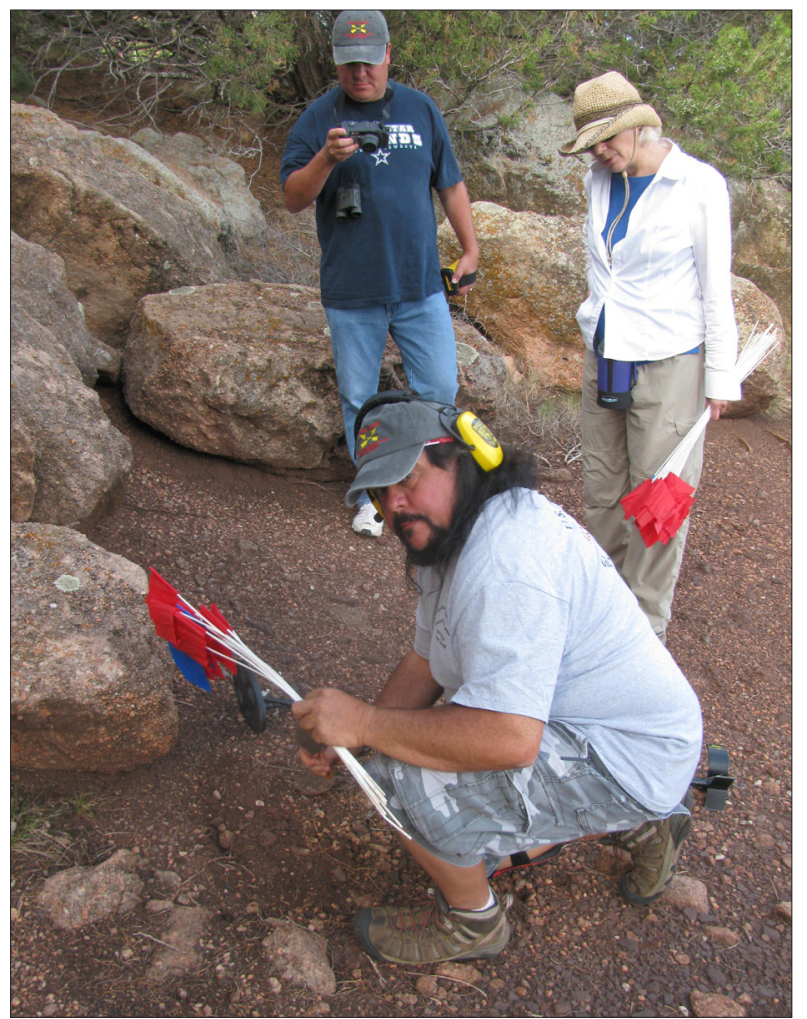

Figure 6. Excavation of a target, Pecos Pueblo Trade Fair Archaeology Reconnaissance Survey Project (Haecker 2012).

\section{Metal Detection Goals and Methods}

As with any well-conceived and well-executed project, pre-fieldwork planning for a metal detection survey program is essential. Key elements typical of any archaeological investigation, such as a scope of work, sufficient background research, and a curation plan also characterize metal detection surveys. Table 1 provides a list of common metal detector survey pitfalls.

Scope of Work

Just like any conventional survey, a metal detection survey requires a scope of work (SOW) that defines the research goals, methods, design, and reporting standards for the project. A plan like this will help identify the appropriate metal detection technical needs and field methods.

It is critical to have all permitting requirements submitted and approved well in advance of conducting the proposed project. Federal, state, or local land management agencies each require specific permits and permissions. Applications for conducting fieldwork that are submitted to federal

Figure 7. Field data collection during a metal detection sample survey, Pecos Pueblo National Monument. The digital collection was done using an Ipad $3^{\circledR}$ Documents to $G o^{\circledast}$ application, recording each metal detected target on a spreadsheet. Another application, Theodolite $H^{\circledR}{ }^{\circledR}$, was used to photograph each excavated artifact. The application recorded position in UTM coordinates, approximate elevation, horizontal angle of the image, and the azimuth of the camera (Scott et al. 2014).

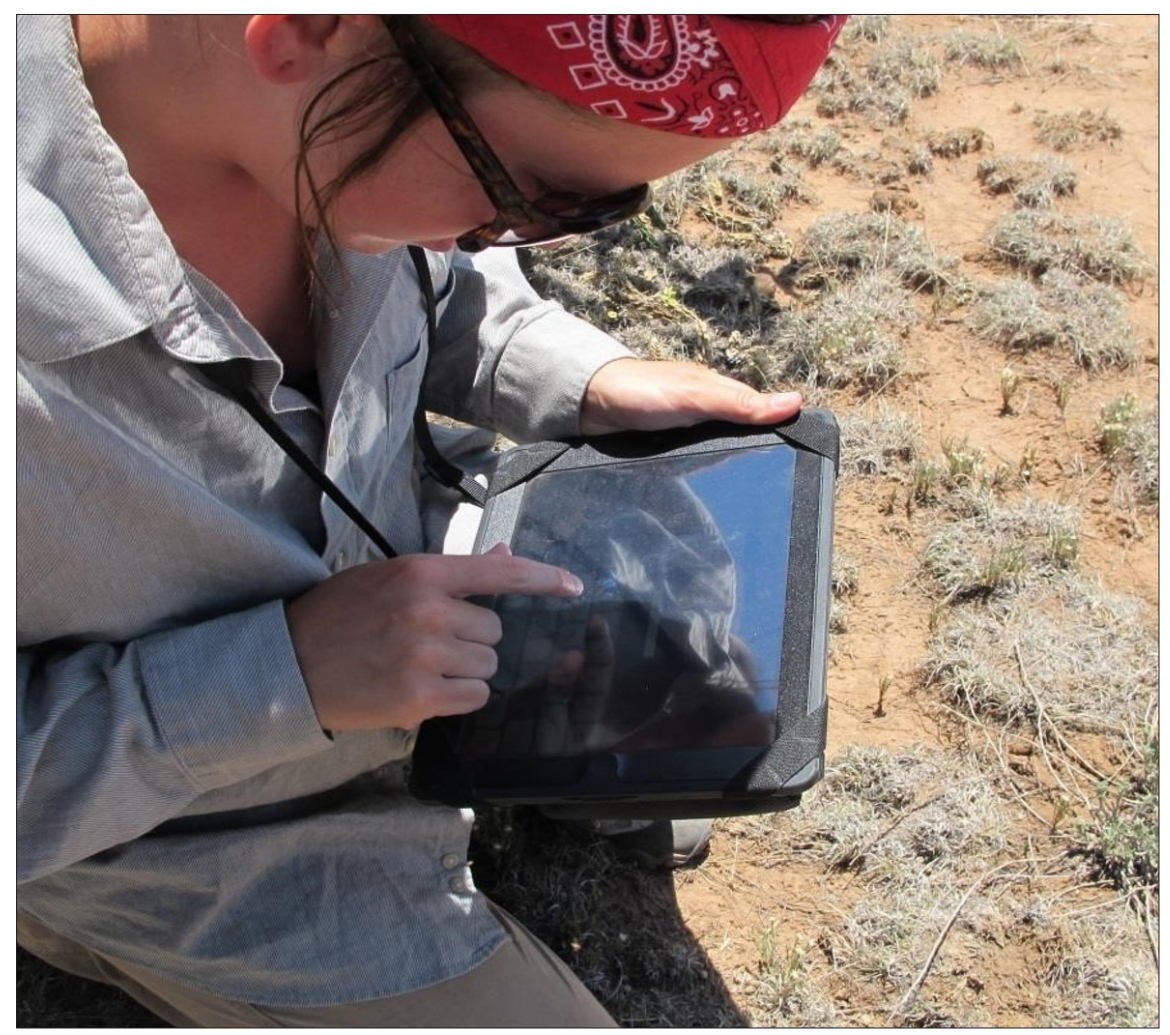




\section{Table 1. A checklist for metal detection fieldwork.}

- Be sure to have a sufficient supply of spare batteries for your metal detector. If the field director is supplying batteries, make sure these batteries are the correct type(s) that will be used by the various machine models during the survey.

- Use only non-metallic pin flags (nylon- or wood-stemmed) and make sure to have enough other supplies for artifact and data collection needs.

- Check to see that you have digging tools appropriate for the soil type(s) to be excavated.

- When excavating a target, plan to not excavate directly down onto the exact location of the target, as this might damage the artifact (figures 10,11, 12).

- If possible, have a hand-held metal-detection pin pointer for use in excavation, as this greatly facilitates in identifying the exact location of the artifact.

- Once the artifact is removed from the hole, remember to run the metal detector over and around the hole to determine if any other metal is present (figure 13).

- Be sure to establish an artifact coding system for recording artifacts in a database either in the field or later (e.g., RB — round ball; CT—cartridge case; and so forth).

- When using a PI machine, wear clothing that lacks metal, remove finger rings, bracelets, and other jewelry, belts, or watches.

- Wear boots or athletic shoes that lack metal; otherwise one might be constantly discovering one's footwear during survey.

- On surveys that employ multiple metal detector makes and models, it is likely there will be electronic signal interference between certain metal detectors. Discover these differences early so that the operators of these machines can be kept a minimum of 10 meters apart during survey.

agencies and SHPO must clearly indicate the intent to conduct metal detection or other remote sensing. Land managing agencies typically require a draft SOW or research proposal for review, and the preparer should provide a justification for metal detection in order to obtain its permission.

The SOW should make clear to the landowner or agency the project goals, proposed field techniques, and collection or non-collection strategy. If the survey involves collection, you will need to include a documentation agreement with an approved curation facility.

The SOW should allow flexibility in the sampling design, so that changes can be made if field conditions demand adjustments in the sampling percentage or method. Remember that the chosen spacing between detectorists has a direct bearing on meeting sampling goals within the scheduled time frame for survey completion (figure 8).

Excavation of a subsurface metallic object takes time, so make a rough estimate of how long it will take to excavate them. For example, if the SOW specifies a 10 percent sample survey of 200 acres to be completed in five days there may difficulty in completing the work if relatively few artifacts are found in the first four days, and then 200 targets are found in three concentrations on the last day. Lack of time may prevent excavation of all of these targets, so it may be necessary to excavate a smaller sample of targets from each concentration sufficient to get a good cross-section of the artifact types, activity areas, and chronological components at the site. The SOW should include a contingency plan if such a situation arises, to ensure that fieldwork can be completed on schedule.

\section{Background Research}

Background research may reveal what types of historic sites are likely to be present and may suggest the most likely categories of metallic artifacts to be found. Research may also reveal the environmental and historical factors that may have influenced the distribution of subsurface and surface artifacts, such as plowing, chaining, and mechanical scraping. Based on this research, one should specify expectations for possible artifact distribution patterns in the project area. For example, one might expect surface or subsurface artifact scatters around military tent pads, along historic trails, or within and around homestead structures. If needed, it may be necessary to engage the services of historical 
Figure 8. Metal

detection sample

survey, Fort Manuel

Lisa Archaeology

Project, Montana.

Transects are spaced

approximately

10 meters apart,

permitting a 10

percent sample survey

of approximately 270

acres, the survey to be

completed in four days

(Haecker and French

2010).

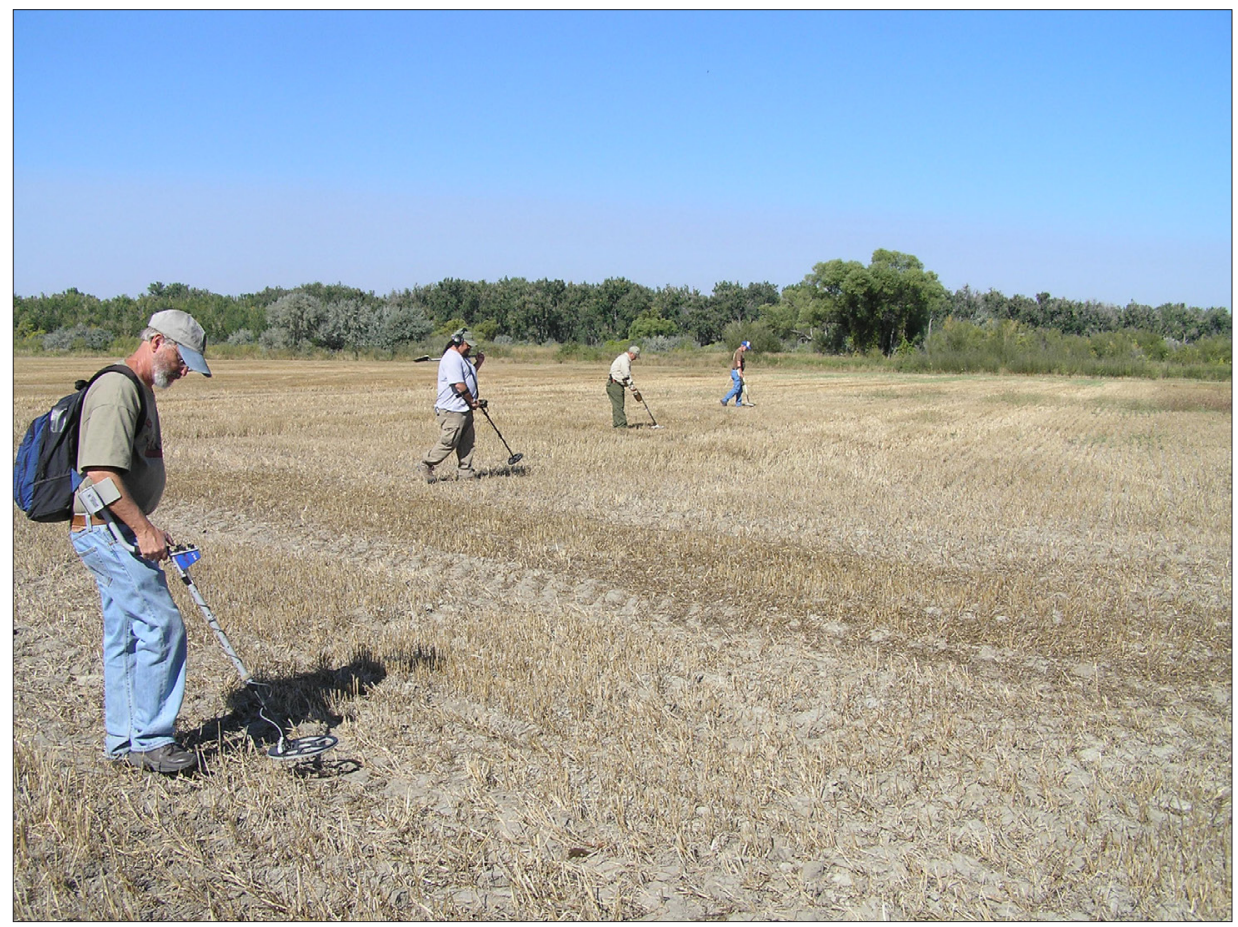

archaeologists who have expertise in identifying expected items such as period military equipage, arms and ammunition, or ranch-related artifacts.

It is also important to determine if relic hunters have compromised the project area. If such is the case, it may be possible to contact these individuals (assuming they can be identified and are willing to discuss with you their findings) to determine what has been removed from the project area.

\section{Physical Inspection of the Project Area}

Prior to the fieldwork, it will help to assess the vegetation cover, as well as other possible obstacles to metal detecting. This information will be needed to determine metal detection field methods. For example, thick vegetation cover may need to be mowed or trimmed within transect lines in order for metal detection to take place (figure 9).

It is also critical to assess localized geologic factors, such as iron-rich igneous rocks that may cause problems for detector models that cannot screen out resultant false readings. If possible, determine if colluvial or alluvial soils have buried the cultural strata to such a depth that only those VLF models or PI machines that can detect metal artifacts at such depths should be used. Finally, attempt to determine the soil types in the area. Sandy soil is relatively easy to excavate with a trowel or other types of hand-held tools, but dense clayey soil will likely require a shovel.

\section{Complementary Remote Sensing Techniques}

If the project budget permits, consider using complementary geophysical techniques, which aid in interpreting subsurface metal artifact concentrations by providing feature information that cannot be obtained from metal detection alone.

\section{To Collect or Not to Collect, That is the Question}

A metal detection survey can generate many hundreds of artifacts. If artifacts are to be collected, sufficient funds must be set aside for curation and metal conservation. Iron retrieved from damp soils may require conservation services, which will require additional curation funds. In addition, fragile artifacts may be found, so be ready for infield "first aid" by having specialized packing materials available. If possible, have a professional curator on the survey team.

If artifacts will be collected, have a signed agreement in place with the landowner allowing 


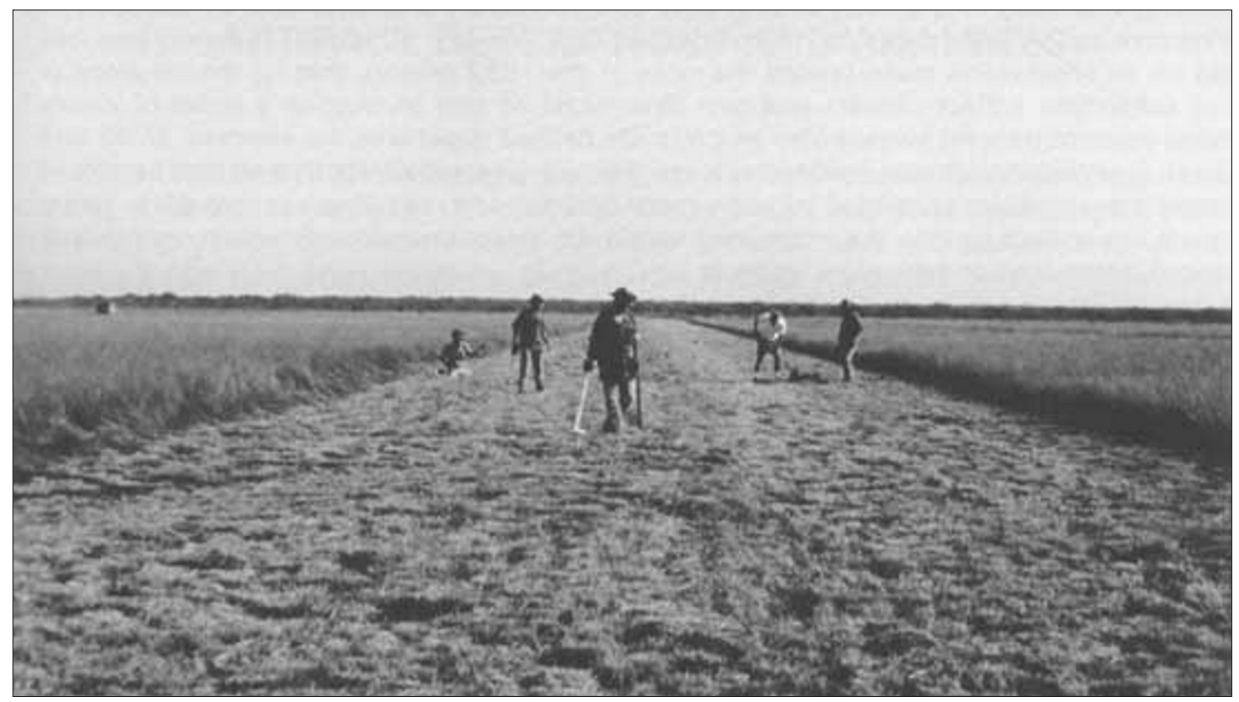

Figure 9. Metal

detection sample

survey of one of seven,

20 by 320 -meter

sample units, which

are demarcated by

mowing the salt

prairie grass. Mowing

permitted surveying

this portion of Palo

Alto Battlefield, Texas

(Haecker 1994).

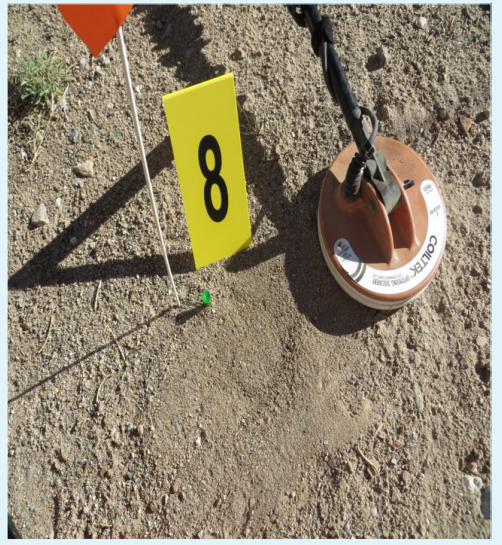

Figures 10-12. Left: Definition of a subsurface metal target, located within a 19th century Apache War battle site, New Mexico. The pinpointed location of the artifact is indicated by placement of a golf tee; Center: An exposed artifact at another targeted location, within the

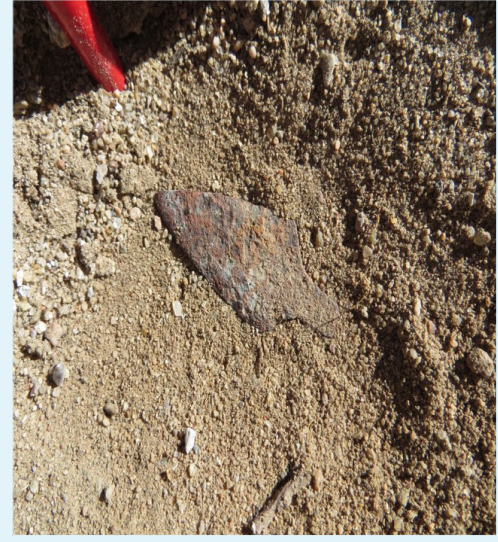

same Apache War battle site. Note the close proximity of the golf tee in relationship to the artifact (photo courtesy Chris Adams). Right: The exposed artifact is an iron arrow point. The excavator is wearing latex gloves to prevent the artifact from being contaminated by

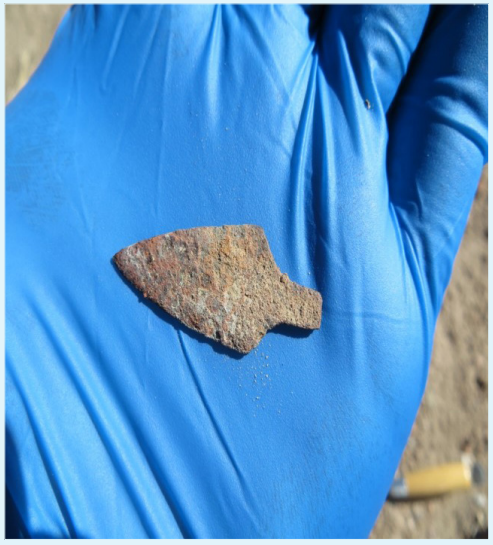

contact with his skin; the artifact will be analyzed for blood protein residue. An arrow point from another Apache War battle site was similarly analyzed, indicating the presence of horse blood (photos courtesy Chris Adams). for the loan of artifacts to conduct off-site artifact analysis. If the project does not call for collection, be prepared for in-field analysis. Have a good quality camera or appropriate mobile device on hand, as well as a scale for photos, calipers and scale for measurements, and a hand lens of at least 10X power for close inspection.

\section{Survey Types and Research Goals: Reconnaissance, Sample, Data Recovery}

Just as for a conventional survey, project goals will drive what survey type will be chosen for an investigation incorporating metal detectors. Of course, this may be in part based on available funds, 


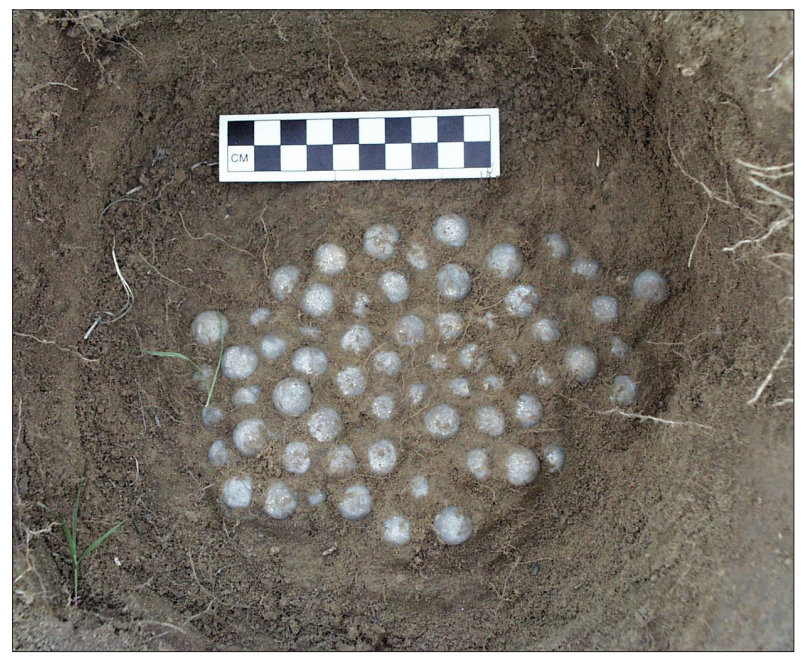

Figure 13. Why it is important to check one's excavation hole a second time: A cache of .58 caliber round balls, Sand Creek Massacre NHS. The detectorist initially discovered one round ball. After removing this ball, he ran his metal detector coil over the hole and identified another ball, which he removed. After several balls had been removed in this fashion, the hole was expanded. There is a total of 178 balls in the cache.

personnel, and time. It is also possible that a metal detection project might use a hybrid combination of survey types. For example, a reconnaissance survey may later employ more robust sampling techniques when the historic sites discovered during reconnaissance are actually recorded.

A reconnaissance survey gathers initial information over a large area, and provides baseline information for the next phase, which might include a sample survey. This type of survey is good at identifying the presence or absence of particular site types. Reconnaissance surveys typically involve widely spaced metal-detector surveyors who are not constrained by transect width or compass bearings; instead, the surveyors follow natural contours of a particular topographic feature, such as a drainage, terrace, hill slope, or ridge crest to discover sites. The actual survey path often resembles a broad zigzag pattern as the surveyor goes around natural obstructions or manmade metallic or electromagnetic anomalies such as power lines or pipelines.

An example of a reconnaissance-level survey is one recently conducted by Gila National Forest
Archaeologist Christopher Adams. Adams is interested in locating Apache encampment sites and accordingly has identified a $40 \mathrm{mi}^{2}$ (103.6 $\mathrm{km}^{2}$ ) project area comprised of high-desert terrain having widely varied topographic relief. Using historical accounts of Apache land use patterns, Adams's survey team employed metal detectors to reconnoiter ridge crests, mesa escarpments, springs, ephemeral drainage terraces and other landform types for potential evidence of Apache activity. Instead of using survey transects, team members followed the rough topographic contours of this landscape. During a particular survey session, one surveyor metal-detected a ridge crest where there was evidence of wickiup rings while another surveyor, located several hundred meters downslope, operated his machine around a rock shelter with Apache pictographs. Once discovered, these features were then more intensively sample surveyed using closely spaced transects (Adams, personal communication, 2015).

By contrast, a sample survey is typically used when documenting the areal extent of a specific cultural resource, such as a battlefield, a large and internally complex encampment, a homestead, or a historic trail. Sample surveys are also conducted within proposed undertakings that might adversely affect historic properties; examples might include a proposed pipeline route, a housing development tract, or a highway right-of-way. Metal-detection sampling of the previously mentioned Thornburg Mountain project area that was slated for oil and gas exploration entailed several surveyors advancing in alignment and spaced approximately 10 meters apart. The surveyors adhered to their correct spacing as they followed a compass bearing; no lathes or other transect guides were required in this case (Scott 2008). This survey technique is commonly used on metal detection projects where the survey area is an open landscape and free of visual obstructions.

Sample size determines the number and distance of the surveyor's spacing. For example, 270 acres comprised the sample universe for the Fort Manuel Lisa Archaeology Project in Cascade County, Montana. During the planning prior to initiating this survey it was decided that four metal-detector surveyors, spaced 10 meters apart, could complete a 10 percent sample, or approximately 27 acres, 
in four days of field time. Fieldwork then focused on intensive metal detection of identified artifact concentrations by means of more closely spaced, informal transects (Haecker and Wegman-French 2010).

Finally, a more intensive and targeted data recovery plan is used when every artifact within a site or feature is deemed important or is in imminent danger of being destroyed. In these cases, the goal is for discovery and recovery of a significant sample or all of the artifacts. The archaeological investigations conducted by RMC Consultants at the previously mentioned Bunker Site (5SH614), in Saguache County, Colorado exemplify a metal detection project with full data recovery. On this project, several two-person teams metal detected a series of transects that encompassed the entire site. Each team was comprised of a metal detector operator, with the other team member placing pin flags at each target location. Target recovery included screening the soil that was removed during excavation of the target area, thereby providing an opportunity to also recover non-metallic artifacts. An artifact was collected if it was determined that it was associated with the site's period of use and possessed research potential. Less significant artifacts were noted and described and then re-buried at the level of discovery (Martorano et al. 2014:55).

Zuni Cultural Resources Enterprise conducted a metal-detection data recovery project at the Zuni ancestral pueblo site of Hawikku, where on July 8, 1540 elements of the Vázquez de Coronado expedition attacked and captured this pueblo. Metal artifacts associated with the attack, as well as the artifact patterning that was documented, held great significance for Zuni Pueblo and offered significant new historic insights to researchers interested in sixteenth-century Spanish entradas. Survey techniques included an initial metaldetection sample survey over the suspected location of the battlefield to determine if Coronado-related artifacts were present. Once this was verified, survey included placement of 20-by-20-m units, which were then intensively metal detected multiple times using closely spaced transects (Damp 2005).

Piedras Marcadas, which is an ancestral Sandia Pueblo site near Albuquerque, New Mexico, is another pueblo that was placed under siege by elements of the Coronado expedition. Data recovery at this site also included intensive metal detection of 20-by-20-m units (Matthew Schmader, personal communication 2007) (figure 14). Again,

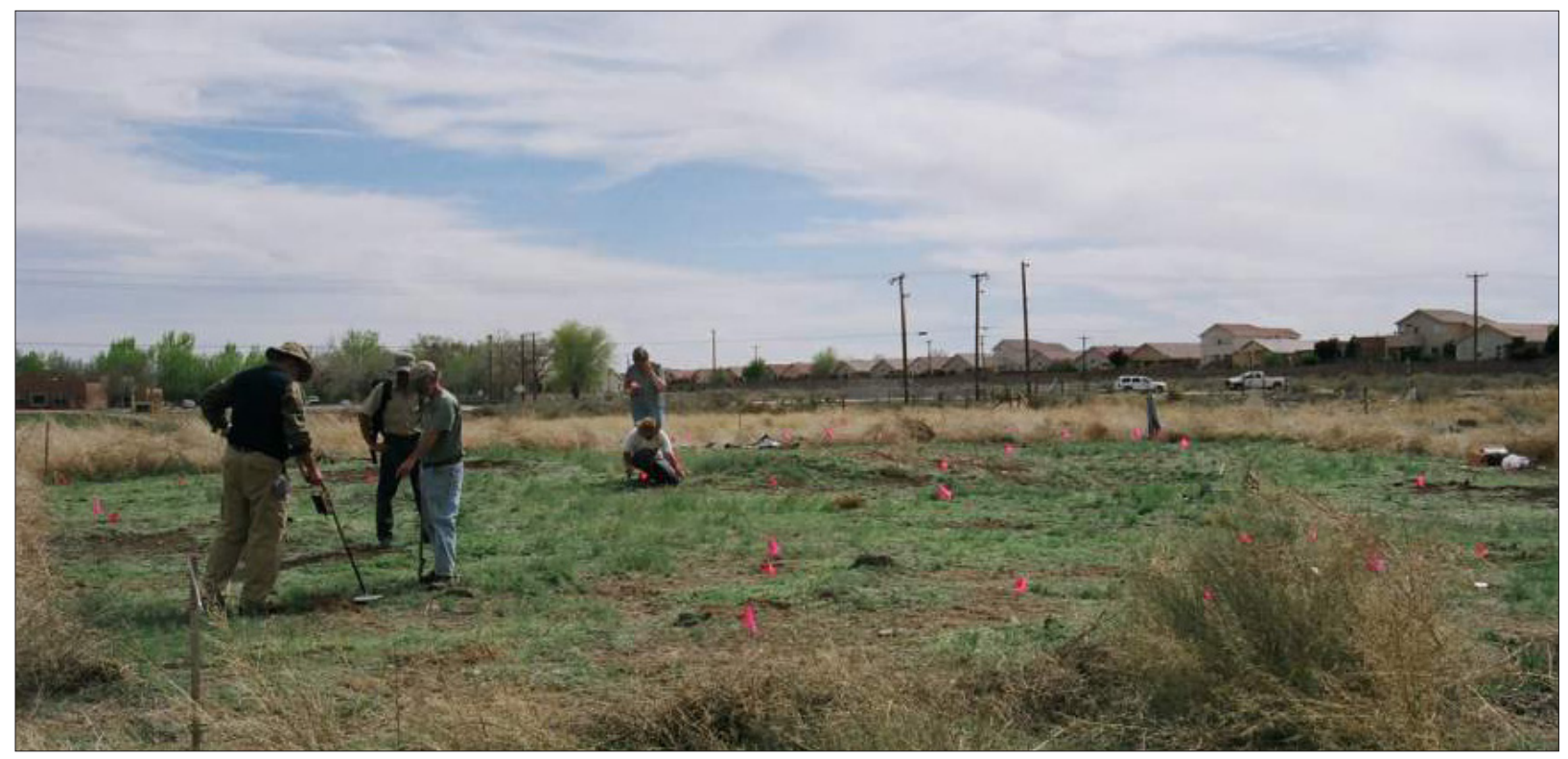

Figure 14. Data recovery within a plaza, Piedras Marcadas Tiguex Ancestral Pueblo Site, New Mexico. Archaeologists are excavating targets, marked with pin flags, within a 20 by 20-meter data recovery unit. Recovered artifacts are associated with a 1540-1541 siege-attack by elements of the Vázquez de Coronado expedition. This nationally significant site requires comprehensive data recovery due to illicit relic collecting 
metal detectors played a key role in the success of the research at this site.

\section{Concluding Remarks}

We hope that this brief review of metal detection in archaeological research has made it clear that a metal detector is not an instrument of the devil; rather, it is an essential remote sensing tool that should be utilized by all historic archaeologists. Like any tool, its user should know its strengths and weaknesses, be familiar with its correct operation, and plan carefully conceived and executed survey projects accordingly. Finally, we strongly recommend that those intending to add metal detection to their repertoire of professional skills take the threeday introductory class offered by Advanced Metal Detecting for the Archaeologist (AMDA [http:// amda.modernheritage.net/]. Additionally, AMDA offers an advanced class for archaeologists who have mastered the basics of metal-detecting. Both classes provide attendees with Register of Professional Archaeologists continuing education credits, offer hands-on experience with a variety of metal detector makes and models, and present various field methods and sampling techniques currently being used by the metal-detection archaeological community.

Acknowledgements. We wish to acknowledge Jonathan Horn (Alpine Archaeological Consultants) and Marilyn Martorano (RMC Consultants, Inc.) for their constructive comments regarding the initial draft of this article. Curtis Martin provided his ideas regarding metal detection survey techniques and research goals. Chris Adams (USFS-Gila National Forest), who has over 30 years of archaeological experience in the use of metal detectors, likewise provided his thoughts regarding metal detection as an important archaeological approach. The authors also thank our fellow instructors of Advanced Metal Detecting for the Archaeologist, for their mutual sharing of metal detection expertise over the years.

\section{References Cited}

Baliki, Joseph, and Christopher T. Espenshade

2010 Doug Scott Military Archaeology, Eastern Style, Status 2010. Journal of Middle Atlantic Archaeology 26:16.

Baxter, Edward P., and Kay L. Killen

1976 A Study of the Palo Alto Battleground, Cameron County, Texas. Report 33. Anthropology Laboratory, Texas A\&M University, College Station, Texas.
Cartier, Robert R. and Frank Hole

1972 San Jacinto Battleground: Archaeological Studies, 1971-1972. Texas Antiquities Committee Permit Report No. 11. Department of Anthropology, Rice University, Houston.

Connor, Melissa, and Douglas D. Scott

1998 Metal Detector Use in Archaeology: An Introduction. Historical Archaeology 32(4):76-85. [doi. org/10.1007/BF03374273]

Damp, Jonathan E.

2005 The Battle of Hawikku, Archaeological Investigations of the Zuni-Coronado Encounter at Hawikku, the Ensuing Battle, and the Aftermath During the Summer of 1540. Zuni Cultural Resources Enterprise Research Series 13. Report on file at ZCRE, Zuni, New Mexico, and NPSAmerican Battlefield Protection Program, Washington, D.C.

Greene, Jerome A.

1986 [1973] Evidence and the Custer Enigma: A Reconstruction of Indian-Military History. Kansas City Posse of the Westerners, Kansas City, Missouri. 1986 facilimile ed. Outbooks, Reno, Nevada.

Greene, Jerome A., and Douglas D. Scott

2004 Finding Sand Creek: History, Archeology, and the 1864 Massacre Site. University of Oklahoma Press, Norman.

Haecker, Charles M.

1994 A Thunder of Cannon: Archeology of the MexicanAmerican War Battlefield of Palo Alto. Southwest Cultural Resources Center Professional Papers 52. National Park Service, Santa Fe, New Mexico.

2002 Archeological Sample Survey of the Florida Mountains, Luna County, New Mexico. National Park Service, Heritage Partnerships Program, Santa Fe, New Mexico.

2011 Metal Detection Sample Survey, Fort Union National Monument, Mora County, New Mexico. National Park Service, Heritage Partnerships Program, Santa Fe, New Mexico.

2012 Metal Detection Sample Survey within the Trade Fair Area, Pecos National Historical Park, New Mexico. National Park Service, Heritage Partnerships Program, Santa Fe, New Mexico.

2014 Section 106 Limited Testing and Survey, Pedro and Sofia Trujillo Homestead NHL (5AL706), Alamosa County, Colorado. National Park Service, Heritage Partnerships Program, Santa Fe, New Mexico.

2015 Sand Creek Massacre National Historic Site, 2014 Metal Detection Sample Survey, with Contributions by Douglas D. Scott and Jeff Campbell. National Park Service, Heritage Partnerships Program, Santa Fe, New Mexico.

Haecker, Charles M. and Lysa Wegman-French

2010 Manuel Lisa's Fort Project: 2009 Site Location Study and Signature Rock Stabilization Plan, Yellowstone and Treasure Counties, Montana. National Park Service, Intermountain Region, Heritage Partnerships Program, Denver, Colorado.

Hardesty, Donald L.

1997 The Archaeology of the Donner Party. University of 
Nevada Press, Reno, Nevada.

Horn, Jonathon C., Jack E. Pfertsh, and Ross S. Curtis 2003 Chapter 28. Cherry Creek Construction Camp5LP1915. In The Mid-America Pipeline Company/ Williams Rocky Mountain Expansion Loop Pipeline Archaeological Data Recovery Project, Northwestern New Mexico, Western Colorado, and Eastern Utah, compiled by Jonathon C. Horn, Jerry Fetterman, and Linda Honeycutt. Alpine Archaeological Consultants, Inc. Report prepared for Williams Energy Services, Tulsa, Oklahoma. On file at the Bureau of Land Management, Utah State Office, Salt Lake City.

Martin, Curtis

2016 Ephemeral Bounty: Wickiups, Trade Goods, and the Final Years of the Autonomous Ute. University of Utah Press, Salt Lake City.

Martin, Curtis, Michael J. Brown, and John E. Lindstrom

2011 The Colorado Wickiup Project Volume VI: Test Excavation of the Black Canyon Ramada (5DT222) and the Documentation of Four Additional Premier Aboriginal Wooden Feature Sites in Colorado. Dominquez Archaeological Research Group, Inc., Grand Junction, Colorado.

Martin, Curtis and Michael J. Brown

2010 The Colorado Wickiup Project Volume V: Test Excavation of the Ute Hunters' Camp (5RB563) and the Documentation of Five Aboriginal Wooden Feature Sites in Rio Blanco County, Colorado. DARG Project D2802. Dominguez Archaeological Research Group, Inc., Grand Junction, Colorado.

Martorano, Marilyn A., Eric Hendrickson, and David Killam 2014 Archeological Testing, Metal Detecting and Dendrochronological Analysis of the Bunker Site (5SH614), Old Spanish National Historic Trail, Rio Grande National Forest, Saguache County, Colorado and the Baca Mountain Tract "New Lands" Cultural Landscape Analysis, Phase I, Saguache County, Colorado. Prepared by RMC Consultants, Inc., Wheat Ridge, Colorado. Submitted to the U.S. Forest Service, Rio Grande National Forest, Monte Vista, Colorado, and Paleocultural Research Group, Arvada, Colorado.

Millward, Sara A., Martha Bright, Matthew J. Landt, Summer Moore, Jenn Mueller, Jaclyn Mullen, Jack E. Pfertsh, and Charles Reed

2012 Cultural Resource Mitigation of Sites along the Nucla-Sunshine 115-Kv Transmission Line, Montrose and San Miguel Counties, Colorado. Prepared by Alpine Archaeological Consultants, Inc., Montrose, Colorado. Submitted to Tri-State Generation and Transmission Association, Inc., Westminster, Colorado.

National Park Service, National Historic Landmarks Program 2005 Travelers Rest (24MO176) NHL Nomination. NPS-Heritage Partnerships Program, Denver, Colorado.

Parrington, Michael, Helen Schenk, and Jacqueline Thibault

1984 The Material World of the Revolutionary War Soldier at Valley Forge. In The Scope of Historical Archaeology: Essays in Honor of John L. Cotter, edited by David Orr and Daniel G. Crozier, pp. 125-162. Occasional Publications of the Department of Anthropology. Temple University, Philadelphia, Pennsylvania.
Scott, Douglas D.

2008 Thornburgh Mountain and the Milk Creek Battle Area, Moffat and Rio Blanco Counties, Colorado: An Archeological Inventory of a Proposed Oil and Gas Lease Area. National Park Service, Midwest Archeological Center, Lincoln, Nebraska.

Scott, Douglas D., and Richard A. Fox, Jr. 1987 Archaeological Insights into the Custer Battle: A Preliminary Assessment. University of Oklahoma Press, Norman, Oklahoma.

Scott, Douglas D., Richard A. Fox, Jr., Melissa A. Connor, and Dick Harmon

1989 Archaeological Perspectives on the Battle of Little Bighorn. University of Oklahoma Press, Norman, Oklahoma.

Scott, Douglas D., Peter Bleed, and Charles Haecker

2014 The Pecos Trade Fair Area: Archeological Investigations of Apache, Comanche, and Spanish-Related Sites at Pecos National Historical Park, New Mexico. Department of Anthropology, University of Nebraska, Lincoln, Nebraska.

\section{Notes}

${ }^{1}$ We cannot recommend any particular brand or model of metal detector as being an optimal, all-purpose machine. Each metal detector brand and model possesses features that may be beneficial in one type of natural environment or archaeological context, but become a liability in a different context. For example, the Tesoro Lobo SuperTraq ${ }^{\oplus}$, manufactured in Arizona and consequently intended for operating on dryalkaline soils, works quite well in the American Southwest. When used in humid regions, however, water condenses in the battery compartment, causing the machine to malfunction until the compartment is thoroughly dried out. Our discussion of particular detectors is for illustration only, and simply reflects our own experience with these devices.

\section{Supplementary Material}

Supplement 1: Connor, Melissa, and Douglas D. Scott

1998 Metal Detector Use in Archaeology: An Introduction. Historical Archaeology 32(4):76-85. [@Society for Historical Archaeology]

\section{Contributor Notes}

Charles M. Haecker received his M.A in Anthropology, Eastern New Mexico University, Portales, in 1976. Since 1973, he has conducted archaeological research throughout the Southeast and Southwest. Charles retired from the National Park Service in 2016, after 23 years of service with NPS. In his last position, he was Program Archaeologist-Heritage Partnerships Program/Intermountain Region. In this position, Charles developed partnerships with various federal and state agencies, Tribes, communities and private citizens, to identify 
archaeological resources that hold national significance. As a specialist in historic archaeology with an emphasis on militaryrelated sites, Charles has conducted, or has participated in, over 45 metal detection survey projects, including: Historic Period Puebloan sites, sites associated with the 1540-1542 Vázquez de Coronado expedition; a 1541 Mixtón War battle site in Mexico; French-and-Indian War and Revolutionary War battlefields and encampments; 17th and 18th centuries Spanish-Colonial sites; 19th century homesteads; U.S.-Mexican War, Civil War, and Indian Wars battlefields and encampments; Apache and Plains Indian habitation sites; an 1803 Tlingit fortification in Alaska; and segments of the Camino Real (1598-1900+) and the Santa Fe Trail (1822-1880+). Since $2015 \mathrm{He}$ has been an instructor with Advanced Metal Detecting for the Archaeologist (AMDA).

Douglas D. Scott retired in 2006 from the National Park Service after more than 30 years of with the Department of the Interior, his last position was as Great Plains Team Leader, Park Programs, Midwest Archeological Center Lincoln, Nebraska. $\mathrm{He}$ is currently Adjunct Research Faculty at Colorado Mesa University. Doug received his Ph.D. in 1977 in Anthropology from the University of Colorado, Boulder. He has worked throughout the Great Plains and Rocky Mountain West on a variety of archeological projects. Doug specializes in nineteenth century military sites archeology and forensic archeology. He is particularly noted for his expertise in battlefield archeology and firearms identification having worked on more than 60 battlefield sites. Doug has also been involved with human rights and forensic investigations since the early 1990s. He has worked with the United Nations and various human rights organizations in El Salvador, Croatia, Rwanda, Cyprus, Iraq, and on an animal welfare case in Canada. Since 2010 he has been a part of an archaeological continuing education program, Advanced Metal Detecting for Archaeologist (AMDA). The program trains supervisory and field personnel in how to employ metal detectors, determine the best device for the job, and determine person hour and coverage expectations among other things

Patrick Severts has over 27 years of archaeological experience and has engaged in surveys and excavations of both prehistoric and historic sites in New Mexico and Georgia. Since 1995 he has utilized a metal detector as his principal means of determining area extent of historic sites. Now residing in Georgia, Patrick has been engaged in metal detection survey projects throughout the Southeast, these projects including the recordation of historic farmsteads, Contact Period Native American sites, and battlefields associated with the Revolutionary War and Civil War. He currently teaches metal detection to students from several universities, at a 19th century factory site located on his property in Georgia. Patrick is considered as one of the leading experts in the archaeological implementation of metal detectors, and is co-founder of Advanced Metal Detecting for the Archaeologist (AMDA), which is associated with the Society for Historical Archaeology. 
